\title{
COVID-19-Related Social Media Fake News in India
}

Md. Sayeed Al-Zaman (D)

Citation: Al-Zaman, M.S. 2021. COVID-19-Related Social Media Fake News in India. Journalism and Media 2: 100-114. https://doi.org/10.3390/ journalmedia2010007

Received: 11 February 2021

Accepted: 11 March 2021

Published: 16 March 2021

Publisher's Note: MDPI stays neutral with regard to jurisdictional claims in published maps and institutional affiliations.

Copyright: (C) 2021 by the author. Licensee MDPI, Basel, Switzerland. This article is an open access article distributed under the terms and conditions of the Creative Commons Attribution (CC BY) license (https:/ / creativecommons.org/licenses/by/ $4.0 /)$.
Department of Journalism and Media Studies, Jahangirnagar University, Savar, Dhaka 1342, Bangladesh; msalzaman@juniv.edu

\begin{abstract}
COVID-19-related online fake news poses a threat to Indian public health. In response, this study seeks to understand the five important features of COVID-19-related social media fake news by analyzing 125 Indian fake news. The analysis produces five major findings based on five research questions. First, the seven themes of fake news are health, religiopolitical, political, crime, entertainment, religious, and miscellaneous. Health-related fake news (67.2\%) is on the top of the list that includes medicine, medical and healthcare facilities, viral infection, and doctor-patient issues. Second, the seven types of fake news contents are text, photo, audio, video, text and photo, text and video, and text and photo and video. More fake news takes the form of text and video (47.2\%). Third, online media produces more fake news (94.4\%) than mainstream media (5.6\%). More interestingly, four social media platforms: Twitter, Facebook, WhatsApp, and YouTube, produce most of the fake news. Fourth, relatively more fake news has international connections (54.4\%) as the COVID-19 pandemic is a global phenomenon. Fifth, most of the COVID-19-related fake news is negative $(63.2 \%)$ which could be a real threat to public health. These results may contribute to the academic understanding of social media fake news during the present and future health-crisis period. This paper concludes by stating some limitations regarding the data source and results, as well as provides a few suggestions for further research.
\end{abstract}

Keywords: fake news; social media; misinformation; COVID-19; public health; India

\section{Introduction}

Fake news challenges human communication, producing tension, misunderstanding, and disbelief. In this age of digital communication and social networking, it gets a new momentum worldwide. Amid the COVID-19 pandemic, the world is in grief with half a million dead; the healthcare systems across the globe are in disarray. In such a situation, online fake news poses a new threat to public health communication as more people now depend on the internet to get health-related information (Mayhew 2020). Meanwhile, the World Health Organization (WHO) states that the pandemic is accompanied by an "infodemic" (i.e., information epidemic). While true information helps to mitigate the pandemic-led crisis, false information may intensify it. For instance, a single medicinerelated fake news claimed at least 800 lives and 5800 more had to admit to hospitals (Coleman 2020). In the scholarly arena, COVID-19-related research surge, and fake news become one of the most important topics of discussion. More studies dealing with COVID19-related online fake news focus on specific either geographical areas (Casero-Ripolles 2020), or language patterns (Rovetta and Bhagavathula 2020), or cross-platform analysis (Cinelli et al. 2020), or information sharing behavior (Rodríguez et al. 2020). Although social media fake news is commonplace in all regions, research endeavors focus only on a few of them. For example, South Asian countries produce ample online fake news but get less attention from the researchers (Al-Zaman 2019). Taking such limitations into account, this study deals with Indian COVID-19-related fake news.

India has been suffering from fake news for the last few years. Fake news not only produces discontent among people but also claims lives, often inviting communal violence and public lynching (Arun 2019; Farooq 2018; Mukherjee 2020). During the COVID-19 
pandemic, like elsewhere in the world, fake news threats India's public health undeniably. For example, fake news is driving towards healthcare denial of religious minorities (Menon 2020). Considering these reasons, the present study of fake news in the Indian context has significance and importance.

Although fake news propagation has been a living crisis in India, the responsible authorities fail to take proper measures to curb the problem. For instance, effective fake news prevention initiatives, such as bills, laws, and punishments, are more frequent in many countries like Canada, China, the USA, France (for the complete list, see Funke and Flamini 2019), whereas, the Indian the government often shuts down the internet (95 times in 2019) to control the problem (Nazmi 2019). Moreover, the country's burgeoning media-illiterate netizens contribute to this problem to some extent (Raj and Goswami 2020). Recently, a few other issues, such as healthcare, medication, disease, religion, and politics, participate in the country's ongoing COVID-19 fake news crisis that demands a better understanding (Kadam and Atre 2020). As a response, this study attempts to answer five research questions based on five basic but important variables of fake news: themes, content types, sources, coverages, and aims. Before that, based on previous literature, the concept of "fake news" is redefined in the following section.

\section{Conceptualizing Fake News}

While fake news is an old phenomenon, it becomes a buzzword after the 2016 US election (Quandt et al. 2019). Fake news is widely accepted as false information, although politicians often use it to discredit investigative journalistic reports (Tandoc et al. 2018). Despite its presence in scholarly discourses, defining fake news needs to answer at least three questions. First, how should we define "fake", "news", and "fake news"? Should "news" be defined as information from a broader perspective or as a journalistic report from a narrower perspective? Which meaning of fake should be used: false or misleading? Second, how should we define the truth value of fake news? Should fake news necessarily be false? Or could it be only misleading with true information? Third, how should we correlate fake news with rumor, misinformation, and disinformation, and to what extent? Scholars hardly come to a consensus for an acceptable definition of fake news and end up defining it in many ways (Higdon 2020). For example, Allcott and Gentzkow (2017) stated that fake news is "intentionally and verifiably false" that could mislead people. In contrast, Jaster and Lanius (2018) argued that fake news may not necessarily be false and it can mislead people even presenting true information. On the other hand, Muigai (2019) defined fake news as false or fabricated information that misleads people, and it can be both deliberate and accidental. Tandoc et al. (2018) analyzed 34 scholarly articles on fake news published between 2003 to 2017 and found its six definitions.

In the present study, for a more convenient definition, I choose to address news as any information that has a narrative body, that has a context, and that has substantial value among the public. Similarly, the term fake refers to pseudo or camouflaged-appears to be real/original and could be true or false. Taking the previous definitions into account, I would state that fake news intentionally or unintentionally misleads people by misrepresenting true information or presenting false information. Fake news is closely associated with rumor, misinformation, and disinformation. Rumor is unverified information that is either true or false but misleads people (Allport and Postman 1946). Misinformation is the unintentional false information that usually emerges from knowledge gaps. Disinformation is the intentional production and dissemination of false information to deceive people (Floridi 2011). Though these three concepts are different from each other, they individually share some common areas with fake news. Thus, fake news is frequently addressed as (a) rumor (e.g., Meel and Vishwakarma 2020) for sharing similar features including ambiguity, uncertainty, and the topic of interest, (b) misinformation (e.g., Wardle 2017) as it may unintentionally mislead people, and (c) disinformation (e.g., Tandoc et al. 2020) as it may be produced and disseminated intentionally to achieve a particular goal. Muigai (2019) stated that misinformation and disinformation are two other terms of fake news. Therefore, 
rumor, misinformation, and disinformation literature would also be relevant in this study. In recent years, fake news coupling with social media has become a novel crisis. Moreover, social media turns the previous passive audiences of the traditional media system into active information-producers. Thus, a paradigm shift takes place in information ecology that is intensifying the fake-news-problem to a greater extent. Fake news usually springs up in ambiguous and threatening situations and when information is scarce and people feel a psychological need for understanding or security (Allport and Postman 1946; Difonzo and Bordia 2006). When uncertainty and ambiguity are reduced to a certain degree and reliable information is provided, fake news disappears. As the COVID-19 pandemic creates a global crisis with uncertainty, ambiguity, and information scarcity, the prevalence of fake news in social media is expected.

\section{COVID-19-Related Online Fake News}

The COVID-19 pandemic experiences a surge in social media fake news. It primarily disrupts public health communication and incites mass anxiety. Meanwhile, as a prompt response, a few studies have already appeared in the scholarly arena that deal with social media fake news. Some researchers investigated fake news propagation from behavioral, cultural, and sociolinguistic perspectives. Using Google Trends, for example, Rovetta and Bhagavathula (2020) analyzed the attitudes of erroneous online information and its consumption from January to March 2020. The result shows that the top scientific and COVID-19-related terms are "novel coronavirus," "China coronavirus," "COVID19," "2019-nCOV," and "SARS-COV-2", along with top-five searched key terms: "face masks," "amuchina" (disinfectant), "symptoms of the novel coronavirus," "health bulletin," and "vaccines for coronavirus." Interestingly, they found that fake news spreads racist information as well. Laato et al. (2020) developed and tested a research model to explore why social media users share COVID-19 fake news. Their results show that "a person's trust in online information and perceived information overload are strong predictors of unverified information sharing" (Laato et al. 2020, p. 1). Pennycook et al. (2020) in their two studies with over 1,600 respondents investigated why people believe and spread COVID-19 fake news. Their finding shows that many people simply fail to determine the truth value of the news and share it. Erku et al. (2020) discussed three tendencies parallel to the pandemic: the growth of fake medicines, fake news, and fake prescriptions. These studies suggest that the COVID-19 pandemic deepens the fake news problem and vice versa.

Some studies show the opposite findings that assert the ongoing fake news pandemic may gradually fade away with time. For example, Casero-Ripolles (2020) in the secondary data analysis found that people are actively consuming information that rises from $60 \%$ during pre-COVID-19-era to $92 \%$ during the pandemic. The study also shows that people's fake news detection capacity increased by $12 \%$ during the pandemic. It is because the information consumption rate is positively correlated with fake news detection capacity. A few researches compare different social media platforms. For example, Cinelli et al. (2020) analyzed data from five social media platforms: Twitter, Instagram, YouTube, Reddit, and Gab, to explore the patterns of COVID-19 information diffusion. The result shows that all platforms have different volumes of fake news and Gab is more susceptible to it. The spreading pattern of COVID-19 information is similar irrespective of platforms, according to the study. Note that Gab is a popular social media platform of far-right political activists and supporters. In another study, Rodríguez et al. (2020) argued that social media users share fake news more than evidence-based news. Well-distributed fake news in social media, according to them, leads to contradictory and poor decision-making. Like Cinelli et al. (2020), this study also analyzed cross-platform data. They retrieved, classified, and compared 1,923 COVID-19-related fake and/or unverified posts from Twitter and Sina Weibo. The result shows that Twitter is more fake-news-prone than Sina Weibo.

Some researches offer a few solutions to the COVID-19-related fake news crisis. Erku et al. (2020) inferred that pharmacists are the key player in health communication. There- 
fore, to reduce medication-related fake news, reliable information from the pharmacists should be distributed to the public and other health professionals. Naeem and Bhatti (2020) suggested preparing COVID-19-related myth busters, fact-checkers, and credible information sources to reduce online fake news. They further suggest compiling and circulate necessary reliable information for the public, students, and faculties to recognize fake news. Political and legislative connections to fake news are also analyzed in several studies. Alvarez-Risco et al. (2020) observed that Peru's strict law (i.e., imprisonment) against fake news was a success. While Peru became more successful to control the fakenews-problem due to the government's stringent step, Dominican Republic struggled with dysfunctional governance (Tapia 2020). Having a weak healthcare infrastructure along with public distrust, the government was losing its battle against the proliferating fake news epidemic. In another study, Gradon (2020) addressed the fake news problem from the perspective of Crime Science. It provides some preventive strategies to reduce fake news propagation and proliferation: counter-narrative and use of AI as countermeasures are two of them. Although social media itself is a well-known producer of fake news, Orso et al. (2020) emphasized its positive use to diffuse necessary medical information. They also suggest filtering social media communication to reduce the pervasiveness of fake news: Laato et al. (2020) offered a similar solution to this problem. In another study, Pennycook et al. (2020) tested an intervention intended to increase the truthfulness of the content people share on social media. They identify that sharing behavior improves after nudging the users to think about news accuracy. They further believe that accuracy nudges could be an immediate fake news prevention technique.

The discussed studies are useful to understand the different aspects of COVID-19 online fake news and possible strategies to control the crisis. At this point, the main concepts/variables of this research should be positioned on the existing literature to identify the knowledge gaps and to better explain the research inquiries. For example, the theme identification of COVID-19 fake news would help to understand the public's topical interest. Along with theme analysis, the following sections also focus on three relevant concepts: contents, sources, and aims of fake news.

\section{Themes and Typologies of Fake News}

Fake news typologies and theme analysis are common in previous literature. I found at least ten typologies that discuss the types of fake news from different perspectives. Tandoc et al. (2018) identified six types of fake news: news satire, news parody, fabrication, manipulation, propaganda, and advertising. Each of them can be defined in terms of facticity and intention. That means some of them have a higher level of facticity and deceptive intentions and some have a lower level of facticity and deceptive intentions. Three similar typologies are also popular among communication scholars. According to Wardle (2017), fake news has seven types: satire or parody, misleading content, imposter content, fabricated content, false connection, false connection, false context, and manipulated content. Studying the 2016 US election, Allcott and Gentzkow (2017) identified seven close cousins of fake news: "unintentional reporting mistakes, fake news that does not originate from a particular news article, conspiracy theories, a satire that is unlikely to be misconstrued as factual false statements by politicians, and reports that are slanted or misleading but not outright false." Mezaris and Teyssou (2019) identified five types of fake news: satire, poor journalism, propaganda, advertising, and false news. Notice that these typologies share some common types (e.g., satire and false news) to define the types of fake news and are more concerned about the claims than the topics of fake news rather than themes.

Two studies propose fake news typologies that make connections among fake news, rumor, misinformation, and disinformation. According to Haque (2019), fake news has four types: disinformation, misinformation, hoax, and rumor. Ouedraogo (2020) divided COVID-19-related social media fake news into six types: maliciously false news, neutral false news, satire news, disinformation, misinformation, and rumor. This study is more relevant to the present one but has the same problem as the previous typologies, that is, it 
is less concerned about the thematic issues of fake news. However, both typologies suggest that fake news is closely related to rumor, misinformation, or disinformation (for more insights, see Duffy et al. 2019).

A few studies present thematic typologies of fake news that are more relevant to this study. Based on media ecology analysis, Higdon (2020) explored four prominent themes of fake news: nationalism, hate, celebrity gossip, and fear. However, this study did not take social media and COVID-19-related fake news into account. In another study, Wu and Liu (2018) identified four themes of social media fake news messages: science and technology, business, entertainment, and medical. This study has three limitations: it is confined in the computer science discipline, it does not offer a detail of the categories, and it does not consider COVID-19 fake news. By a content analysis of 225 COVID-19-related fake news, Brennen et al. (2020) explored nine themes: public authority action or policy (39\%), community spread (24\%), general medical advice and virus characteristics (24\%), prominent actors $(23 \%)$, conspiracy theories $(17 \%)$, virus transmission $(16 \%)$, explanation of virus origin (12\%), public preparedness $(6 \%)$, and vaccine development and availability $(5 \%)$. However, this study considers only medical-related fake news, avoiding other relevant topics, such as politics, religion, and entertainment, that can also contribute to fake news production related to COVID-19. Two more relevant studies dealt with Indian fake news. Al-Zaman (2021) presented a typology of fake news: health, religion, politics, crime, entertainment, and miscellaneous. In a similar study, Kanozia et al. (2021) identified a few more themes of fake news: economy, education, sports, international, and historical. In another study conducted in Bangladesh explored seven themes of fake news, emphasizing religiopolitical fake news as a separate category (Al-Zaman et al. 2020). Overall, the previous studies have at least one of the three following limitations: (a) their findings are not COVID-19-related; (b) their findings are not related to social media; (c) their findings are not inclusive enough to consider diverse fake news themes.

\section{Content Types of Fake News}

Analysis of fake news content types helps to understand how true news is different from fake news. Researchers propose at least three parameters to determine this difference: writing style, the number of linguistic elements, and expressions (as cited in Zhou and Zafarani 2020). Only a few previous studies are concerned with fake news content, focused on form analysis, theme analysis, style analysis, and message analysis. For example, a thematic analysis of Khan et al. (2019) suggested that fake news has five types of content: clickbait, satire and parody, propaganda, sloppy news, and biased or partisan news. This typology firstly echoes the fake news typology of Tandoc et al. (2018) and secondly defines fake news from a more journalistic perspective. Although Guacho et al. (2018) talked about three fake news contents: text, image, and video, their study only focuses on the textual analysis of fake news articles. Similarly, Wheaton (2018) stated about the text, image, and video, focusing only on textual analysis. A few more studies analyze different types of fake news contents, such as text (e.g., Guacho et al. 2018; Wheaton 2018), image (e.g., Carlson 2009), video (e.g., Mezaris and Teyssou 2019), text and image (e.g., Zhou and Zafarani 2020). However, Parikh and Atrey (2018) presented probably the most comprehensive typology of fake news content analyzing different news stories. They categorized fake news data into four types: (a) text data from the linguistic aspect (i.e., article, written post, blog); (b) multimedia data indicating multiple forms of media (i.e., image, video, audio, and graphics); (c) hyperlinks that connect different sources, such as a web page, snapshot, sound clip; (d) audio as a standalone category, such as the podcasts. This study has a few limitations. First, the types overlap. If audio can be a standalone type, then why not video and image? Second, a hyperlink may not be a major content type of fake news as it depends on other types. Third, this typology is somewhat affected by redundancy. Multimedia itself can define several forms of media content. Important to note that online fake news can take more than one form at a specific time and previous studies hardly acknowledged this uniqueness. For example, Al-Zaman (2021) and Kanozia et al. (2021) emphasized 
the combined content types, such as photo with text, video with text, and produced a comprehensive typology of fake news contents: text, photo, video, audio, text and photo, text and video, photo and video, text and photo \% video. Notice that the first four are primary content types and the others are combined content types. However, the previous studies fail to present the findings related to COVID-19 social media fake news.

\section{Sources of Fake News}

Scholars show less interest in identifying a typology of fake news sources. Kapferer (1992) discussed eight primary sources of fake news: confidential information, fantasies, troubling facts, urban legends, testimony, experts' opinions, misunderstandings, and manipulation. On the other hand, Jo (2002), taking only media sources into account, identified two main sources of internet rumors: the internet itself and traditional mass media. The internet includes different online news sources, whereas traditional media indicates television, newspaper, and radio. The study also shows that online rumors increase with time, while mainstream rumors decrease. Muigai (2019) found that fake news mostly originates from and spreads through online media rather than mainstream media. Shin et al. (2018) identified two main sources of social media fake news by analyzing their Twitter dataset: traditional and non-traditional media. The study shows that more fake news is from non-traditional sources. According to their definition, non-traditional media includes websites, social media, and other internet sources. Kanozia et al. (2021) addressed four major social media platforms as the main sources of fake news in India. On the other hand, Al-Zaman (2021) identified that most of the fake news in India has two primary sources: mainstream media and online media. The previous studies on source identification of social media fake news have two problems: they either do not consider the social media fake news problem and/or their context is different from the pandemic period. It is important to mention that social media has now become a more effective tool to (re)produce and (re)distribute information. Moreover, virality brings success to fake news and social media facilitates this process (Tandoc et al. 2018).

\section{Aims of Fake News}

The terms "aim" and "intention" were used a few previous studies to denote tendencies and claims of fake news. Dowd and Davidhizar (1997) categorized rumor's intentions as wish, fear or bogey, wedge-driving or aggressive, and anticipatory. Wish rumor look for prospects and can attract the audiences' attention with its fanciful and/or irrational representation of future benefits and/or hopes. Dread rumors usually stir up fear, have longer life spans, have more prevalence, and have higher persuasive value compared to wish rumors. Fueled by stereotypes and hatred, wedge-driving rumors attempt to polarize societies, whereas anticipatory rumors expect some specific outcomes in the future that are more-or-less like wish rumors. Surveying consumers to understand marketplace rumors, Kamins et al. (1997) explored two types of aims: positive and negative. In that survey, the consumers reported that they were exposed to and transmitted more negative rumors than positive rumors. The survey findings were tested in two experiments afterward to validate the results. According to Knapp (1944), a positive rumor usually predicts wishful or positive outcomes and a negative rumor describes undesirable or harmful outcomes. Bordia et al. (2006) also found similar aims in their study on health-related rumors. Negative rumors $(n=479 ; 93.92 \%)$ were more prevalent than positive rumors $(n=31 ; 6.08 \%)$ in their sample. Another study shows almost similar results, i.e., negative fake news (91\%) is more commonplace in social media than positive fake news (9\%) (Avaaz 2019). Rosnow et al. (1986) classified fake news as positive and negative based on their consequences. Some more studies have similar findings (e.g., Ji et al. 2020). However, like the theme-, content-, and source-related literature, these studies also do not take COVID-19 online fake news into account to analyze the aims. 
Considering the gaps in the previous literature and the importance of understanding social media fake news related to COVID-19, this study tries to answer the following research questions:

RQ1: What are the popular COVID-19-related themes of social media fake news?

RQ2: What are the different content types of COVID-19-related social media fake news?

RQ3: What are the prevalent sources of COVID-19-related social media fake news?

RQ4: What are the aims of COVID-19-related social media fake news?

RQ5: What are the coverage patterns of COVID-19-related social media fake news?

\section{Research Methods}

Data source: In this study, I analyzed COVID-19-related social media fake news in India following a quantitative content analysis method. The fake news data were collected from Alternative News (http://altnews.in accessed on 1 May 2020), an Indian fact-checking website. It works as a wing of the Pravda Media Foundation, a non-profit organization, and run by professional journalists and media specialists. The International Fact-Checking Network (IFCN), a part of Poynter Institute, certifies it by analyzing six relevant aspects: organization, nonpartisanship and fairness, transparency of sources, transparency of funding and organization, transparency of methodology, and open and honest correction policy. The website is also listed in the database of The Reporters' Lab at Duke University managed by Bill Adair and Mark Stencel. Bill Adair is also the founder of PolitiFact (http:/ / politifact.com accessed on 1 May 2020), a Pulitzer-winner nonprofit fact-checking website. To further verify the website's credibility as a data source, I studied its operational, strategic, and ethical policies. It has three clearly-stated editorial policies: (a) no political affiliations; (b) evidence-based fact-checking; (c) a detailed explanation of how a claim is debunked. Moreover, it maintains the five following methodologies to debunk a claim. First, selection of a claim to debunk. It debunks claims from multiple sources, such as mainstream media, social media, politicians' claims, and popular public discourses. Case selection depends on three criteria: how viral is the claim (extent, reach, and spread), what is the source of the claim (broadcaster, sharer, and discussants), and what is the nature of the claim (provocative, considerable influence and impact). Second, researching the claim. It uses at least seven techniques to verify the information, including analyzing the primary sources, contacting responsible authorities and experts, and using tools like InVid. Third, the evaluation of the claims. Based on comprehensive research, the editorial board decides the truth value of the information. When the information for fact-check is dubious or not conclusive, the fact-checkers decide not to provide a judgment, rather they mention it in the article. Fourth, writing the fact-check. After a decision is made, they prepare a user-friendly but detailed article on the information. The articles also include the sources of evidence so that readers can verify the information by themselves. Fifth, updating the articles. They always keep their eyes for the relevant information to update the most novel evidence. Based on complaints and/or reliable evidence, they acknowledge their errors and correct them promptly. Previous studies also used this fact-checking website as a source of their research data (Al-Zaman 2021; Kanozia et al. 2021).

The website has been debunking Indian fake news from April 2016 onward. Until April 2020, it debunked approximately 2028 fake news. Every article on this website debunks a single fake news, including a few specific information: the statement/claim of the fake news accompanied by a detailed context, the sources of the information along with links, screenshots, or contents (upon availability), and a decision explained in detail backed up by evidence. This website was used as the data source in this research due to three reasons: (a) the comprehensiveness, rich fake news list, and reputation of the website make it a good source for research data; (b) social media platforms often remove flagged and /or distorted information if it violates the platforms' policies so that many pieces of fake news cannot be found by searching the platforms (Mosseri 2017); (c) a few studies used fact-checking websites as data sources because these websites' structured data require less effort to clean and prepare for the final analysis (Brennen et al. 2020; Avaaz 2019). 
At first, the articles published on this website between 29 January to 11 April 2020 were studied. (This timeline has relevance with the COVID-19 situation in India. The country's first COVID-19 case was detected on 30 January 2020 and on 11 April 2020, the number of cases increased to 7529 with 242 dead, according to the Ministry of Health and Family Welfare (MoHFW) of the Government of India.) The website debunked 125 social media fake news directly linked to the pandemic during this period. The four fake-news-prone social media platforms are Twitter, Facebook, YouTube, and WhatsApp. Figure 1 shows that COVID-19 fake news were uneven throughout the time.

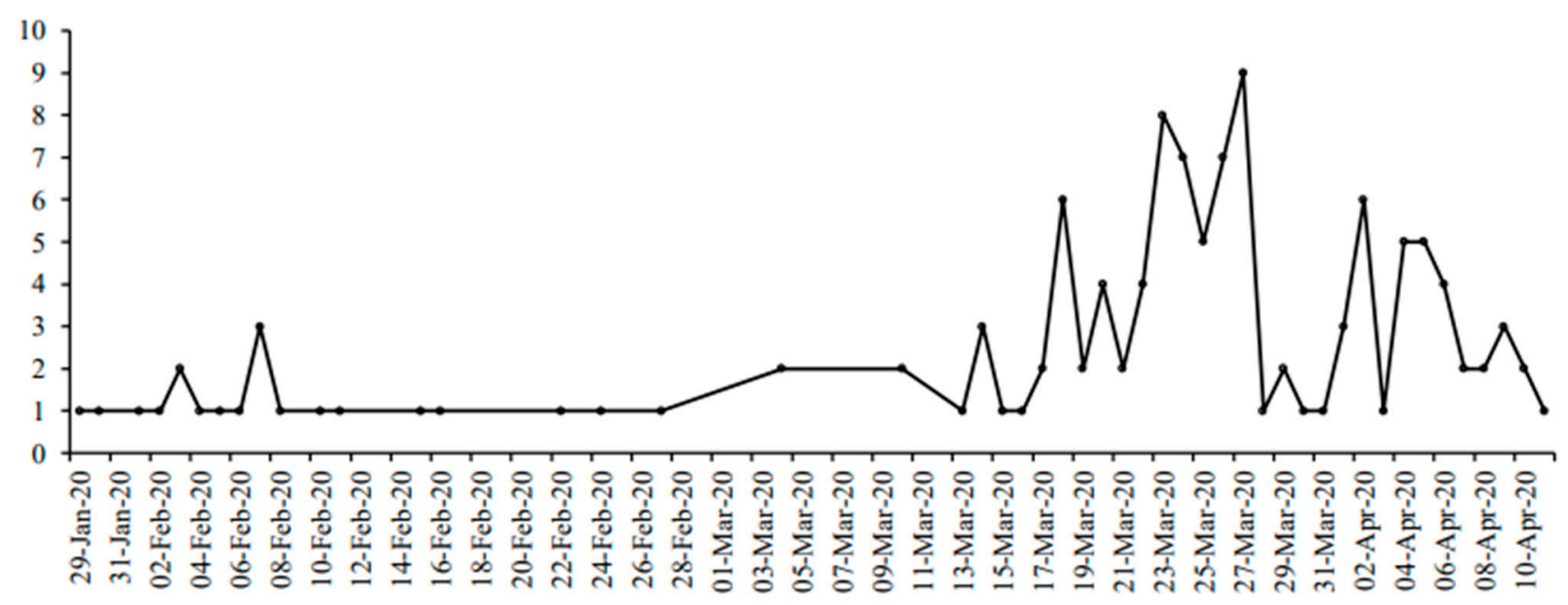

Figure 1. Timeline of fake news.

The number of fake news increased slightly after 27 February but dropped after 10 March. It increased again after 16 March and fluctuates constantly before reaching its peak on 27 March $(n=9 ; 7.2 \%)$. Again, the number dropped starkly the next day, on 28 March $(n=1 ; 0.8 \%)$ (see Table 1$)$. Before another heavy fluctuation, the number reached the third-highest on 2 April $(n=6 ; 4.8 \%)$. However, the curve shows a decline in daily cases from 9 April onward.

Coding technique: Two trained coders coded the collected data. As a quantitative content analysis, this paper used a deductive and fixed coding approach, which means the codes were pre-determined, derived from the previous studies, and the data were collected according to the codes. For RQ1, we derived seven codes for fake news themes from the two previous studies: health, political, religiopolitical, religious, crime, entertainment, and miscellaneous (Al-Zaman 2021; Al-Zaman et al. 2020). In this study, health- and crime-related fake news mainly dealt with medicine, medical and healthcare facilities, viral infection, doctor-patient issues, and quarantine; entertainment fake news was linked to celebrities and popular culture. Important to note that political, religiopolitical, and religious fake news are three different categories. Political fake news was related to institutional politics, political issues, and political figures. If political fake news was somehow found connected to religion, it was considered as religiopolitical fake news. Such fake news chiefly dealt with religious policy, communalism, and mass mobilization. Religious fake news seems less harmful that deals with spirituality, practices, and divinity. For example, "Chinese people are embracing Islam to stay safe from Coronavirus" was a religious fake news, "Muslim fruit seller is licking fruits to spread Coronavirus among the Hindus" was a religiopolitical fake news, and "18 nations including the USA and the UK want Modi to lead a COVID-19 task force" was a political fake news. The miscellaneous fake news included the fake news that did not fit in the other six categories. For RQ2, we derived seven codes from the previous literature for the types of fake news content: text, photo, audio, video, text and photo, text and video, and text and photo and video (AlZaman 2021; Guacho et al. 2018; Kanozia et al. 2021; Parikh and Atrey 2018; Wheaton 2018), 
because we found that a fake news story could take more than one form at a time. For RQ3, we derived two codes for the primary sources of fake news: online media and mainstream media(Al-Zaman 2021). We used two categories from the previous studies: positive and negative, adding "unknown" as a third category for RQ4 (Avaaz 2019; Bordia et al. 2006; Kamins et al. 1997; Knapp 1944). A new category was introduced as the aims of some fake news were unclear. It is to mention that unlike a few previous experimental studies, aim detection in this study was more subjective, depending on the coders' understanding of the claims of fake news, descriptions, and/or impacts. In this regard, Knapp's (1944) definition (i.e., positive rumor usually predicts wishful or positive outcomes while negative rumor describes undesirable or harmful outcomes) guided the coding to some extent. Only for RQ5, we set two codes: national and international. National fake news only deals with national phenomena, whereas international fake news includes fake news that is internationally circulated, having any international connection with other countries, or refer something that is foreign/international. The coders at first examined $48 \%(n=60)$ of the selected sample and found the coding reliable: the additional coding issues were resolved based on discussions and mutual consent.

Table 1. Frequency distributions of fake news.

\begin{tabular}{|c|c|c|c|c|c|c|c|}
\hline Serial & Date & Frequency & Percent & Serial & Date & Frequency & Percent \\
\hline 1 & 27-Mar-20 & 9 & 7.2 & 26 & 10-Apr-20 & 2 & 1.6 \\
\hline 2 & 23-Mar-20 & 8 & 6.4 & 27 & 29-Jan-20 & 1 & 0.8 \\
\hline 3 & 24-Mar-20 & 7 & 5.6 & 28 & 30-Jan-20 & 1 & 0.8 \\
\hline 4 & 26-Mar-20 & 7 & 5.6 & 29 & 1-Feb-20 & 1 & 0.8 \\
\hline 5 & 18-Mar-20 & 6 & 4.8 & 30 & 2-Feb-20 & 1 & 0.8 \\
\hline 6 & 2-Apr-20 & 6 & 4.8 & 31 & 4-Feb-20 & 1 & 0.8 \\
\hline 7 & 25-Mar-20 & 5 & 4.0 & 32 & 5-Feb-20 & 1 & 0.8 \\
\hline 8 & 4-Apr-20 & 5 & 4.0 & 33 & 6-Feb-20 & 1 & 0.8 \\
\hline 9 & 5-Apr-20 & 5 & 4.0 & 34 & 8-Feb-20 & 1 & 0.8 \\
\hline 10 & 20-Mar-20 & 4 & 3.2 & 35 & 10-Feb-20 & 1 & 0.8 \\
\hline 11 & 22-Mar-20 & 4 & 3.2 & 36 & 11-Feb-20 & 1 & 0.8 \\
\hline 12 & 6-Apr-20 & 4 & 3.2 & 37 & 15-Feb-20 & 1 & 0.8 \\
\hline 13 & 7-Feb-20 & 3 & 2.4 & 38 & 16-Feb-20 & 1 & 0.8 \\
\hline 14 & 14-Mar-20 & 3 & 2.4 & 39 & 22-Feb-20 & 1 & 0.8 \\
\hline 15 & 1-Apr-20 & 3 & 2.4 & 40 & 24-Feb-20 & 1 & 0.8 \\
\hline 16 & 9-Apr-20 & 3 & 2.4 & 41 & 27-Feb-20 & 1 & 0.8 \\
\hline 17 & 3-Feb-20 & 2 & 1.6 & 42 & 13-Mar-20 & 1 & 0.8 \\
\hline 18 & 4-Mar-20 & 2 & 1.6 & 43 & 15-Mar-20 & 1 & 0.8 \\
\hline 19 & 10-Mar-20 & 2 & 1.6 & 44 & 16-Mar-20 & 1 & 0.8 \\
\hline 20 & 17-Mar-20 & 2 & 1.6 & 45 & 28-Mar-20 & 1 & 0.8 \\
\hline 21 & 19-Mar-20 & 2 & 1.6 & 46 & 30-Mar-20 & 1 & 0.8 \\
\hline 22 & 21-Mar-20 & 2 & 1.6 & 47 & 31-Mar-20 & 1 & 0.8 \\
\hline 23 & 29-Mar-20 & 2 & 1.6 & 48 & 3-Apr-20 & 1 & 0.8 \\
\hline 24 & 7-Apr-20 & 2 & 1.6 & 49 & 11-Apr-20 & 1 & 0.8 \\
\hline 25 & 8-Apr-20 & 2 & 1.6 & & Total & 125 & 100 \\
\hline
\end{tabular}

Note. The website identifies 125 fake news in a time span of 84 days.

\section{Results}

For RQ1, social media fake news related to COVID-19 has seven dominant themes: health, religiopolitical, political, crime, entertainment, religious, and miscellaneous. Healthrelated fake news has the highest frequencies $(n=84 ; 67.2 \%)$, followed by religiopolitical fake news $(n=21 ; 16.8 \%$ ) with a huge gap in-between (Table 2$)$. These two themes comprise $84 \%$ of the total fake news. Only $2(1.6 \%)$ miscellaneous fake news is found that is the lowest on the list. 
Table 2. Themes of fake news.

\begin{tabular}{ccccc}
\hline Rank & Themes & Frequency & Percent & $\begin{array}{c}\text { Cumulative } \\
\text { Percent }\end{array}$ \\
\hline 1 & Health & 84 & 67.2 & 67.2 \\
2 & Religiopolitical & 21 & 16.8 & 84.0 \\
3 & Political & 9 & 7.2 & 91.2 \\
4 & Crime & 3 & 2.4 & 93.6 \\
5 & Entertainment & 3 & 2.4 & 96.0 \\
6 & Religious & 3 & 2.4 & 98.4 \\
7 & Miscellaneous & 2 & 1.6 & 100.0 \\
& Total & 125 & 100.0 & \\
\hline
\end{tabular}

For RQ2, fake news in social media has seven types of content: text, photo, audio, video, text and photo, text and video, and text and photo and video. Text and video $(n=59 ; 47.2 \%)$ is the most popular combination of fake news contents, followed by another combination: text and photo $(n=40 ; 32 \%)$ (Table 3$)$. Both combinations constitute $79.2 \%$ of the total contents. Photo as a content type has the lowest $(n=1 ; 0.8 \%)$ instance on the list. Three other main content types are also less popular: text $(n=14 ; 11.2 \%)$; audio $(n=6$; $4.8 \%)$; and video $(n=3 ; 2.4 \%)$.

Table 3. Types of Contents.

\begin{tabular}{ccccc}
\hline Rank & Content Types & Frequency & Percent & $\begin{array}{c}\text { Cumulative } \\
\text { Percent }\end{array}$ \\
\hline 1 & Text and Video & 59 & 47.2 & 47.2 \\
2 & Text and Photo & 40 & 32.0 & 79.2 \\
3 & Text & 14 & 11.2 & 90.4 \\
4 & Audio & 6 & 4.8 & 95.2 \\
5 & Video & 3 & 2.4 & 97.6 \\
6 & Text and Photo and Video & 2 & 1.6 & 99.2 \\
7 & Photo & 1 & .8 & 100.0 \\
& Total & 125 & 100.0 & \\
\hline
\end{tabular}

For RQ3, the two main sources of fake news in social media are online media and mainstream media. Of the two types, online media $(n=118)$ alone is responsible for $94.4 \%$ fake news, whereas mainstream media $(n=7)$ is responsible for only $5.6 \%$ of fake news (Table 4).

Table 4. Sources of fake news.

\begin{tabular}{ccccc}
\hline Rank & Source types & Frequency & Percent & $\begin{array}{c}\text { Cumulative } \\
\text { Percent }\end{array}$ \\
\hline 1 & Online media & 118 & 94.4 & 94.4 \\
2 & Mainstream media & 7 & 5.6 & 100.0 \\
& Total & 125 & 100.0 & \\
\hline
\end{tabular}

This uneven distribution suggests that online media is a far more effective fake news source amid COVID-19 than mainstream media. In online media, four social media platforms produce most of the fake news: Twitter $(n=35)$, Facebook $(n=30)$, WhatsApp $(n=4)$, and YouTube $(n=3)$.

For RQ4, the aims of social media fake news related to COVID-19 are of three types: negative; positive; and unknown. More fake news is found negative $(n=79 ; 63.2 \%)$, whereas positive news is significantly lower $(n=28 ; 22.4 \%)$ (Table 5$)$. The aims of $18(14.4 \%)$ fake news are undetected. 
Table 5. Aims of fake news.

\begin{tabular}{ccccc}
\hline Rank & Aims & Frequency & Percent & $\begin{array}{c}\text { Cumulative } \\
\text { Percent }\end{array}$ \\
\hline 1 & Negative & 79 & 63.2 & 63.2 \\
2 & Positive & 28 & 22.4 & 85.6 \\
3 & Unknown & 18 & 14.4 & 100.0 \\
& Total & 125 & 100.0 & \\
\hline
\end{tabular}

For RQ5, international fake news $(n=68 ; 54.4 \%)$ is relatively more popular than national fake news $(n=57 ; 45.6 \%)$ (Table 6$)$.

Table 6. Coverages of fake news.

\begin{tabular}{ccccc}
\hline Rank & Coverages & Frequency & Percent & $\begin{array}{c}\text { Cumulative } \\
\text { Percent }\end{array}$ \\
\hline 1 & International & 68 & 54.4 & 54.4 \\
2 & National & 57 & 45.6 & 100.0 \\
& Total & 125 & 100.0 & \\
\hline
\end{tabular}

\section{Discussion and Conclusions}

Main Objectives and Key Findings: This study seeks to explore the themes, content types, sources, coverages, and aims of COVID-19-related social media fake news from India. A sample of 125 fake news was analyzed. I found that popular fake news fluctuates over the period with a surge at the end of March 2020. Indian users shared and disseminated more COVID-19 fake news when tension escalated, information became scarce, and the demand for information was higher (Raj and Goswami 2020). It could be a reason for this surge that is consistent with the findings of Difonzo and Bordia (2006) and Allport and Postman (1946) that is rumors surge with tension and when an information vacuum is created. Moreover, it seems fake news decreased slowly after 9 April. Two reasons for this could be: (a) initiatives from the authorities and volunteers, such as the government (MoHFW), social media companies (Facebook), and resource persons (doctors), to curb fake news propagation (Dore 2020); (b) a better flow of accurate information against the distorted information, along with the increased information consumption rate among public (Bharti and Mondal 2020). Casero-Ripolles (2020) also explored that the increased information consumption rate and fake news detection capacity have a positive correlation, which means the more the users consume information, the less the prevalence of fake news will be. However, with the repeated fluctuation over the period, this study cannot firmly state that fake news will be decreasing gradually.

Of the seven fake news themes, health-related fake news is on the top that mainly includes topics such as fake medicine (e.g., "Alcohol, weed cure coronavirus infection"), fake information regarding medical and healthcare facilities (e.g., "Medicine will be sprayed in the air to kill coronavirus"), and lockdown rumors (e.g., "Muslims are being punished in India for breaking lockdown"). It contradicts a finding of Brennen et al. (2020) that found policy-related COVID-19 fake news is more prominent. Media reports that fake prescriptions and medicines circulated in social media increased the sale of medical products, deceiving many Indians (ToI 2020). A similar finding shows that most health-related COVID-19 fake news is related to vaccines and medical facilities (Erku et al. 2020). Often the fake news is driven by economic benefit (Tandoc et al. 2018), which means Indian health-related fake news could be intended to generate profit by increasing the sale of fake medical products. It suggests why the sale of medical products increased in India during the pandemic. Note that COVID-19 health-related fake news is not exclusive in India. Rather, it is a common phenomenon around the world, emerged from the health-related tensions and uncertainties. Religiopolitical fake news, such as "Muslim vendors are spreading coronavirus in Surat", is also prominent in India during the pandemic. Such fake news, 
emerging from communal intentions, mostly targets Muslim minorities to demean them. Relevant and recent (religio)political incidents like the Delhi Riot, Citizenship Amendment Act (CAA), National Register of Citizens (NRC) contributed to religiopolitical fake news (Kanozia et al. 2021; Sutaria 2020). As a consequence of religiopolitical and religious fake news and Indian media's Islamophobic contents, Muslim patients were denied healthcare services in many Indian hospitals (Vetticad 2020). Like India, COVID-19 religious fake news is also common in other regions, such as the MENA region and Bangladesh (Alimardani and Elswah 2020; Al-Zaman 2020).

Of the seven COVID-19-related fake news content types, primary contents seem less popular than their combined categories, which means more fake news takes more than one content type at a specific time. For example, more fake news takes the forms of text and photo, followed by text and video: both are the combinations of three different primary content types and have a four-fifth share of the total percentage. A recent survey found that social media usage in India increased $75 \%$ during the pandemic, and the content consumption pattern indicates the rise of text, photo, and video consumption (Keelery 2020). It supports the results of this study to some degree. This result suggests that visual digital contents are more conducive for fake news. Previous studies also found the same that visual-based fake news contents are consumed more in India than other contents (Al-Zaman 2021; Kanozia et al. 2021). One reason of this could be that such contents are easier to spread through instant messaging application (Farooq 2018). Studies also found that WhatsApp, an instant messaging application, is highly popular in India, and a popular tool for spreading fake news as well (Farooq 2018; Mukherjee 2020). Other studies explored that Facebook and its instant messaging application Messenger are responsible for more fake news in India than WhatsApp and Twitter (Kanozia et al. 2021).

The source identification of fake news in social media leads to an interesting finding. Online media produce most of the fake news except a few from mainstream media, which is similar to the findings of Shin et al. (2018), Jo (2002), and Muigai (2019). Moreover, the four social media platforms: Twitter, Facebook, WhatsApp, and YouTube, contribute remarkably to the fake news production and dissemination. Of them, Twitter produces more fake news, perhaps due to its unique and quick information dissemination capacity (as cited in Tandoc et al. 2018). It contradicts the findings of Mukherjee (2020) and Arun (2019) who stated that WhatsApp is responsible for most of the fake news in India. On the other hand, as stated earlier, Kanozia et al. (2021) explored Facebook as the leading social media platform that spread most of the fake news. This result (i.e., online media produces most of the fake news), supporting the finding of Rodríguez et al. (2020), also indicates how important online media can be in terms of fake news production and how important it is to monitor social media to reduce the propagation and proliferation of COVID-19 fake news. Orso et al. (2020) and Laato et al. (2020) prescribed a similar solution to this problem, i.e., filtering and monitoring social media news and communication.

Most COVID-19-related fake news is negative, which can have detrimental impacts on the healthcare system and public health communication. Negative fake news conveys false or misleading information regarding medication, medical facilities, and death, increasing public anxiety. With a less-efficient healthcare system compared to many developed countries, negative fake news could hinder proper healthcare in India. Notice that this result supports the findings of multiple studies from various disciplines (Avaaz 2019; Bordia et al. 2006; Kamins et al. 1997; Knapp 1944) that infers fake news is negative in most cases, irrespective of topics and disciplines. Another finding of this study shows that people are more interested in international than national fake news as more COVID-19related fake news has international connections, such as "Unrelated video viral as Italian police arresting men during COVID-19 lockdown" [sic] or "Dead bodies in Mecca shared as Corona-victims" [sic]. Such fake news has either international references, or national issues having international connections, or international presence. COVID-19 caused a global pandemic in this networked era; therefore, this result is expected. Many COVID-19-related fake news in social media covers national and local issues as well. 
Strengths and Limitations: This study has a few limitations. First, the collected data are from the Indian context that has exceptional political ambience, cultural exceptionalities, technological penetration, communication patterns, and news consumption patterns, which would be more relatable to Bangladesh and Pakistan, and which would be more different from the countries like the USA and the UK (Al-Zaman 2019; Al-Zaman et al. 2020). Moreover, the collected data are not cross-cultural that might cause a generalizationproblem. Second, the data are collected from a fact-checking website and such websites often have a lack of resources to collect a vast array of data (Brennen et al. 2020). Therefore, it may have impacts on the results as well. This study has strengths from a few aspects. First, it utilized fact-checking websites for fake news data, which is a relatively novel source of data. It would attract more researchers and inspire them to build a stronger methodology. Second, important variables of COVID-19 fake news, such as themes, content types, sources, were largely overlooked in academic scholarships. While many studies dealt with Indian fake news (Al-Zaman 2021; Kanozia et al. 2021; Raj and Goswami 2020). This study explored what themes of COVID-19-related fake news are popular in India to what extent, what types of fake news content are more popular among social media users. The source and aim analyses may suggest how to deal with communication media to reduce the negative fake news production and dissemination. These results may also be useful to comprehend the thematic importance of different online fake news and their popularities among netizens.

Overall, this study would provide some novel insights to academics and policymakers to understand COVID-19 fake news more in-depth and to control fake propagation to a certain degree. Although this study produced some relevant results, a few knowledgegaps still exist: why COVID-19-related fake news in social media increases or decreases? What are the consumption patterns of social media content in India during the COVID-19 pandemic, and why?

Funding: This research received no external funding.

Institutional Review Board Statement: Not applicable.

Informed Consent Statement: Not applicable.

Conflicts of Interest: The authors declare no conflict of interest.

\section{References}

Alimardani, Mahsa, and Mona Elswah. 2020. Online Temptations: COVID-19 and Religious Misinformation in the MENA Region. Social Media + Society 6: 2056305120948251. [CrossRef]

Allcott, Hunt, and Matthew Gentzkow. 2017. Social Media and Fake News in the 2016 Election. Journal of Economic Perspectives 31: 211-36. [CrossRef]

Allport, Gordon W., and Leo Postman. 1946. An Analysis of Rumor. Public Opinion Quarterly 10: 501. [CrossRef]

Alvarez-Risco, Aldo, C. R. Mejia, J. Delgado-Zegarra, S. Del-Aguila-Arcentales, A. A. Arce-Esquivel, M. J. Valladares-Garrido, M. Rosas del Portal, L. F. Villegas, W. H. Curioso, M. C. Sekar, and et al. 2020. The Peru Approach against the COVID-19 Infodemic: Insights and Strategies. The American Journal of Tropical Medicine and Hygiene 103: 583-86. [CrossRef]

Al-Zaman, M. Sayeed. 2019. Digital Disinformation and Communalism in Bangladesh. China Media Research 15: 68-76.

Al-Zaman, M. Sayeed. 2020. Healthcare Crises in Bangladesh during the COVID-19 Pandemic. The American Journal of Tropical Medicine and Hygiene 103: 1357-59. [CrossRef] [PubMed]

Al-Zaman, M. Sayeed. 2021. Social Media Fake News in India. Asian Journal for Public Opinion Research 9: 25-47. [CrossRef]

Al-Zaman, M. Sayeed, Sifat A. Sife, Mushfiqa Sultana, Mahbuba Akbar, Kazi T. S. Ahona, and Nandita Sarkar. 2020. Social Media Rumors in Bangladesh. Journal of Information Science Theory and Practices 8: 77-90. [CrossRef]

Arun, Chinmayi. 2019. On WhatsApp, Rumours, and Lynchings. Economic and Political Weekly 54: 30-36.

Avaaz. 2019. US 2020: Another Facebook Disinformation Election? In Facebook Uncovered: Vol 01. New York: Avaaz.

Bharti, Misha, and Jeba B. Mondal. 2020. Steps Taken towards Curbing of Fake News in India. LatestLaws.com. Available online: http:/ /latestlaws.com/articles/steps-taken-towards-curbing-of-fake-news-in-india (accessed on 1 May 2020).

Bordia, Prashant, Elizabeth Jones, Cindy Gallois, Victor J. Callan, and Nicholas DiFonzo. 2006. Management Are Aliens!: Rumors and Stress during Organizational Change. Group and Organization Management 31: 601-21. [CrossRef]

Brennen, J. S., F. M. Simon, P. N. Howard, and R. K. Nielsen. 2020. Types, Sources, and Claims of COVID-19 Misinformation. London: University of Oxford. 
Carlson, Matt. 2009. The reality of a fake image news norms, photojournalistic craft, and brian walski's fabricated photograph. Journalism Practice 3: 125-39. [CrossRef]

Casero-Ripolles, Andreu. 2020. Impact of COVID-19 on the media system: Communicative and democratic consequences of news consumption during the outbreak. El Profesional de La Información 29. [CrossRef]

Cinelli, M., W. Quattrociocchi, A. Galeazzi, C. M. Valensise, E. Brugnoli, A. L. Schmidt, P. Zola, F. Zollo, and A. Scala. 2020. The COVID-19 Social Media Infodemic. Scientific Reports. [CrossRef] [PubMed]

Coleman, A. 2020. "Hundreds dead" because of Covid-19 misinformation. BBC News. Available online: http:/ / bbc.com/news/world53755067 (accessed on 13 September 2020).

Difonzo, N., and P. Bordia. 2006. Rumor Psychology: Social and Organizational Approaches. Washington, DC: Amer Psychological Assn.

Dore, B. 2020. How are Indian Scientists Fighting fake News about COVID-19? World Economic Forum. Available online: https: //www.weforum.org/agenda/2020/04/indian-scientists-covid19-false-infomation-coronavirus (accessed on 2 May 2020).

Dowd, S. B., and R. Davidhizar. 1997. Rumors and gossip in radiology. Radiology Management 19: 46-49. [PubMed]

Duffy, A., E. Tandoc, and R. Ling. 2019. Too good to be true, too good not to share: The social utility of fake news. Information, Communication and Society 23: 1965-79. [CrossRef]

Erku, D. A., S. A. Belachew, S. Abrha, M. Sinnollareddy, J. Thomas, K. J. Steadman, and W. H. Tesfaye. 2020. When fear and misinformation go viral: Pharmacists' role in deterring medication misinformation during the "infodemic" surrounding COVID19. Research in Social and Administrative Pharmacy 17: 1954-63. [CrossRef] [PubMed]

Farooq, G. 2018. Politics of Fake News: How WhatsApp Became a Potent Propaganda Tool in India. Media Watch 9: 106-17. [CrossRef]

Floridi, L. 2011. The Philosophy of Information. London: Oxford University Press.

Funke, D., and D. Flamini. 2019. A Guide to Anti-Misinformation Actions around the World. Poynter. Available online: http: // poynter.org/ifcn/anti-misinformation-actions/ (accessed on 1 May 2020).

Gradon, K. 2020. Crime in the time of the plague: Fake news pandemic and the challenges to law-enforcement and intelligence community. Society Register 4: 133-48. [CrossRef]

Guacho, G. B., S. Abdali, N. Shah, and E. E. Papalexakis. 2018. Semi-supervised content-based detection of misinformation via tensor embeddings. Paper presented at 2018 IEEE/ACM International Conference on Advances in Social Networks Analysis and Mining, ASONAM 2018, Barcelona, Spain, August 28-31; pp. 322-25. [CrossRef]

Haque, M. 2019. "Fake news" in social media: Conceptualizing, detection and finding ways of prevention. Nirikkha 223 : 9-18.

Higdon, Nolan. 2020. What is Fake News? A Foundational Question for Developing Effective Critical News Literacy Education. Democratic Communiqué 29: 1-18.

Jaster, R., and D. Lanius. 2018. What is Fake News? Versus XLVII: 207-24. [CrossRef]

Ji, Peinan, Xi Yan, and Guang Yu. 2020. Can Rumor Clarification Eliminate the Effects of Rumors?: Evidence From China. International Journal of Asian Business and Information Management (IJABIM) 11: 48-62. [CrossRef]

Jo, D. G. 2002. Diffusion of Rumors on the Internet. The Information Society Review 2002: 77-95.

Kadam, Abhay B., and Sachin R. Atre. 2020. Negative impact of social media panic during the COVID-19 outbreak in India. Journal of Travel Medicine, 27. [CrossRef]

Kamins, M. A., V. S. Folkes, and L. Perner. 1997. Consumer Responses to Rumors: Good News, Bad News. Journal of Consumer Psychology 6: 165-87. [CrossRef]

Kanozia, R., R. Arya, S. Singh, G. Ganghariya, and S. Narula. 2021. A Study on Fake News Subject Matter, Presentation Elements, Tools of Detection, and Social Media Platforms in India. Asian Journal for Public Opinion Research 9: 48-82. [CrossRef]

Kapferer, J.-N. 1992. How rumors are born. Society 29: 53-60. [CrossRef]

Keelery, S. 2020. COVID-19 Impact on Media Consumption by Type of Media 2020. Available online: http://statista.com/statistics/11 13485/india-coronavirus-impact-on-media-consumption-by-media-type/ (accessed on 5 May 2020).

Khan, S. A., M. H. Alkawaz, and H. M. Zangana. 2019. The Use and Abuse of Social Media for Spreading Fake News. Paper presented at 2019 IEEE International Conference on Automatic Control and Intelligent Systems, I2CACIS 2019-Proceedings, Selangor, Malaysia, June 29; pp. 145-148. [CrossRef]

Knapp, R. H. 1944. A Psychology of Rumor. Public Opinion Quarterly 8: 22. [CrossRef]

Laato, S., A. K. M. N. Islam, M. N. Islam, and E. Whelan. 2020. What drives unverified information sharing and cyberchondria during the COVID-19 pandemic? European Journal of Information Systems 29: 288-305. [CrossRef]

Mayhew, F. 2020. Poll suggests shift from print to digital will last beyond pandemic. Press Gazette. Available online: pressgazette.co. uk/poll-more-people-consuming-news-digitally-than-in-print-during-pandemic-lockdown/ (accessed on 1 September 2020).

Meel, P., and D. K. Vishwakarma. 2020. Fake news, rumor, information pollution in social media and web: A contemporary survey of state-of-the-arts, challenges and opportunities. Expert Systems with Applications 153: 112986. [CrossRef]

Menon, S. 2020. Coronavirus: The human cost of fake news in India. BBC News. Available online: https://www.bbc.com/news/worldasia-india-53165436 (accessed on 1 February 2021).

Mezaris, V., and D. Teyssou. 2019. Video Verification in the Fake News Era. Berlin/Heidelberg: Springer.

Mosseri, A. 2017. Working to Stop Misinformation and False News. Facebook Media. Available online: http://about.fb.com/news/2017 /04/working-to-stop-misinformation-and-false-news/ (accessed on 1 August 2020).

Muigai, J. W. W. 2019. Understanding Fake News. International Journal of Scientific and Research Publications (IJSRP) 9: 29-38. [CrossRef] 
Mukherjee, R. 2020. Mobile witnessing on WhatsApp: Vigilante virality and the anatomy of mob lynching. South Asian Popular Culture 18: 79-101. [CrossRef]

Naeem, S. B., and R. Bhatti. 2020. The Covid-19 'infodemic': A new front for information professionals. Health Information and Libraries Journal 37: 233-39. [CrossRef]

Nazmi, S. 2019. Why India shuts down the internet more than any other democracy. BBC News. Available online: http://bbc.com/ news / world-asia-india-50819905 (accessed on 1 August 2020).

Orso, D., N. Federici, R. Copetti, L. Vetrugno, and T. Bove. 2020. Infodemic and the spread of fake news in the COVID-19-era. European Journal of Emergency Medicine, Publish Ah 27: 327-28. [CrossRef]

Ouedraogo, N. 2020. Social Media Literacy in Crisis Context: Fake News Consumption during COVID-19 Lockdown. SSRN Electronic Journal, 1-43. [CrossRef]

Parikh, S. B., and P. K. Atrey. 2018. Media-Rich Fake News Detection: A Survey. Paper presented at Proceedings-IEEE 1st Conference on Multimedia Information Processing and Retrieval MIPR, Miami, FL, USA, April 10-12; pp. 436-41. [CrossRef]

Pennycook, G., J. McPhetres, Y. Zhang, and D. Rand. 2020. Fighting COVID-19 misinformation on social media: Experimental evidence for a scalable accuracy nudge intervention. Psychological Science 31: 770-80. [CrossRef]

Rodríguez, Pulido, C., B. Villarejo Carballido, G. Redondo-Sama, M. Guo, M. Ramis, and R. Flecha. 2020. False news around COVID-19 circulated less on Sina Weibo than on Twitter. How to overcome false information? International and Multidisciplinary Journal of Social Sciences 9: 107-28. [CrossRef]

Quandt, T., L. Frischlich, S. Boberg, and T. Schatto-Eckrodt. 2019. Fake News. In The International Encyclopedia of Journalism Studies. Edited by T. P. Vos, F. Hanusch, M. Geertsema-Sligh, A. Sehl and D. Dimitrakopoulou. Wiley Blackwell: vol. 114, pp. 1-6. [CrossRef]

Raj, A., and M. P. Goswami. 2020. Is fake news spreading more rapidly than COVID-19 in India? Journal of Content, Community and Communication 11: 208-20. [CrossRef]

Rosnow, R. L., J. H. Yost, and J. L. Esposito. 1986. Belief in rumor and likelihood of rumor transmission. Language and Communication 6: 189-94. [CrossRef]

Rovetta, A., and A. S. Bhagavathula. 2020. COVID-19-Related Web Search Behaviors and Infodemic Attitudes in Italy: Infodemiological Study. JMIR Public Health and Surveillance 6: e19374. [CrossRef] [PubMed]

Shin, J., L. Jian, K. Driscoll, and F. Bar. 2018. The diffusion of misinformation on social media: Temporal pattern, message, and source. Computers in Human Behavior 83: 278-87. [CrossRef]

Sutaria, S. 2020. Coronavirus Misinformation in India Is Not Limited to Health Misinformation. Available online: https: / / meedan. com/reports / coronavirus-misinformation-in-india-is-not-limited-to-health-misinformation/ (accessed on 1 August 2020).

Tandoc, E. C., D. Lim, and R. Ling. 2020. Diffusion of disinformation: How social media users respond to fake news and why. Journalism 21: 381-98. [CrossRef]

Tandoc, E. C., Z. W. Lim, and R. Ling. 2018. Defining “Fake News": A typology of scholarly definitions. Digital Journalism 6: 137-53. [CrossRef]

Tapia, L. 2020. COVID-19 and Fake News in the Dominican Republic. The American Journal of Tropical Medicine and Hygiene 102: 1172-74. [CrossRef]

ToI. 2020. Coronavirus myth vs. Fact: WhatsApp forward claiming turmeric and black pepper home remedy to cure COVID-19 is fake. Times of India (ToI). Available online: http:/ / timesofindia.indiatimes.com/life-style/health-fitness/health-news/coronavirusmyth-vs-fact-whatsapp-forward-claiming-turmeric-and-black-pepper-home-remedy-to-cure-covid-19-is-fake/photostory / 76995286.cms (accessed on 7 September 2020).

Vetticad, Anna M. M. 2020. Indian Media Accused of ISLAMOPHOBIA for its Coronavirus Coverage. [Newspaper]. Al Jazeera. Available online: https://www.aljazeera.com/news/2020/5/15/indian-media-accused-of-islamophobia-for-its-coronaviruscoverage (accessed on 30 December 2020).

Wardle, C. 2017. Fake News. It's Complicated. First Draft. Available online: https://firstdraftnews.org/latest/fake-news-complicated/ (accessed on 1 May 2020).

Wheaton, Gracie Claire. 2018. Birthers, Hand Signals, and Spirit Cooking: The Impact of Political Fake News Content on Facebook Engagement during the 2016 U.S. Presidential Election. Master's thesis, Virginia Polytechnique Institute and State University, Blacksburg, VA, USA. Available online: http://vtechworks.lib.vt.edu/handle/10919/89055 (accessed on 1 May 2020).

$\mathrm{Wu}$, Liang, and Huan Liu. 2018. Tracing Fake-News Footprints. Paper presented at Eleventh ACM International Conference on Web Search and Data Mining-WSDM, Los Angeles, CA, USA, Ferbuary 6-8; vol. 18, pp. 637-45. [CrossRef]

Zhou, Xinyi, and Reza Zafarani. 2020. A Survey of Fake News: Fundamental Theories, Detection Methods, and Opportunities. ACM Computing Surveys 53: 1-34. [CrossRef] 